\title{
Circulating yersinia specific immune complexes after acute yersiniosis: a follow up study of patients with and without reactive arthritis
}

\author{
RIITTA LAHESMAA-RANTALA,' KAISA GRANFORS.' \\ RIITTA KEKOMÄKI, ${ }^{3}$ AND AULI TOIVANEN ${ }^{12}$ \\ From the Departments of ${ }^{1}$ Medical Microbiology and ${ }^{2}$ Medicine, Turku University, Turku; and the ${ }^{3}$ Finnish \\ Red Cross Blood Transfusion Service, Helsinki, Finland
}

SUMMARY The occurrence of immune complexes (ICs) containing Yersinia enterocolitica antigen and immunoglobulin was studied in 216 serum samples from 51 patients with recent yersiniosis at an early stage of the disease and during a follow up of two to 12 months. Twenty eight of the patients developed reactive arthritis, 23 recovered from the infection without any complications. An enzyme linked immunosorbent assay (ELISA) recently developed for detection of ICs containing yersinia antigen(s) and $\operatorname{IgM}, \operatorname{IgG}$, or $\operatorname{IgA}$ was applied. During the first two months after onset of the infection yersinia specific IgM complexes were demonstrated in higher concentrations in patients with arthritis than in those not developing this postinfection complication $(\mathrm{p}<0.02)$. The difference in the occurrence of IgM complexes between the two groups decreased with time. Yersinia specific IgA complexes were demonstrable in four patients with arthritis and in none of the non-arthritic patients. Yersinia specific IgG complexes were occasionally present in both patient groups. Altogether, more than eight months after onset of the infection yersinia specific ICs were detected in six arthritic and two non-arthritic patients, suggesting that in certain individuals yersiniae may hide after the initial infection for prolonged periods.

It has been suggested that immune complexes (ICs) may have a role in the pathogenesis of reactive arthritis, particularly since the symptoms of postinfection complications to some extent resemble those seen in IC diseases. ${ }^{1}$ In a patient with polyarthritis after salmonella infection the level of circulating ICs correlated with severity of the disease. ${ }^{2}$ There is also evidence of certain similarities between reactive arthritis and $\mathrm{IgA}$ mediated glomerulonephritis, suggesting that the same pathogenetic mechanisms may be active in both. $\operatorname{IgA}$ nephropathy has been reported in two patients with ankylosing spondylitis and in one with Reiter's disease. ${ }^{3}$ Forsström et al first reported IgA nephropathy connected with yersinia arthritis, ${ }^{4}$ and later Friedberg et al found yersinia antigens in the glomeruli of five patients out of eight with glomerulonephritis triggered by yersinia

Accepted for publication 23 July 1986.

Correspondence to Dr Riitta Lahesmaa-Rantala. Department of Medical Microbiology. Turku University. SF-20520 Turku. Finland. infection. ${ }^{5}$ Interestingly, circulating ICs containing $\operatorname{IgA}$ were recently found to correlate with the severity of psoriatic arthritis ${ }^{6}$ and of an experimentally induced lung injury. ${ }^{7}$ Kekomäki et al measured ICs in patients with yersiniosis using four antigen non-specific methods detecting mainly IgG complexes; circulating ICs were frequently found both in arthritic and non-arthritic patients. ${ }^{8}$ A significant disappearance of circulating ICs was seen in arthritic patients early during the follow up when compared with those with prolonged gastroenteritis. Also, Leirisalo et al found circulating, antigen nonspecific ICs in patients after acute yersiniosis, irrespective of whether or not they developed arthritis. ${ }^{9}$

In the present study occurrence of ICs containing yersinia antigen was analysed in the sera of patients with acute yersiniosis at an early stage of the disease and during a follow up. Patients with reactive arthritis were compared with those having recovered from the infection without complications and with healthy controls. 


\section{Patients and methods}

\section{PATIENTS}

All the 51 patients studied had acute infection with $Y$ enterocolitica $\mathrm{O}: 3$. The diagnosis was based on the considerably raised levels of antibodies to yersinia detected by ELISA ${ }^{1011}$ and the clinical picture. $Y$ enterocolitica $\mathrm{O}: 3$ was isolated from the faeces of 20 patients. All patients had abdominal pain or diarrhoea, or both. Fever and raised erythrocyte sedimentation rate were usually present. Two of the patients were operated upon for suspected appendicitis; the appendix was not inflamed, and yersiniosis was diagnosed both bacteriologically and serologically. Twenty eight patients developed reactive arthritis and 23 recovered without complications. The follow up period ranged from three to 12 months in 25 patients with arthritis, and in 17 patients without arthritis. From three patients with arthritis and from six patients without arthritis samples were taken only during the first two months. The follow up time was divided into periods of two months; the sample giving the highest IC value was chosen to represent each patient during each period. The patients were divided according to the grade of arthritis into three groups: (a) patients who had only gastroenteritis without any postinfection complications, $(b)$ patients who had grade + arthritis with their own recording of joint symptoms or mild synovitis verified by the physician, and $(c)$ patients with severe grade ++ arthritis verified by the physician. Distribution of HLA-B27, age, and sex of the patients is shown in Table 1.

Two series of patient sera were studied. The first series consisted of 69 samples from 15 patients (eight women and seven men), which had earlier been studied for occurrence of antigen non-specific ICs by Kekomäki et al. ${ }^{\times}$Of these patients, nine had gastroenteritis only and six developed arthritis. The sera had been stored for six years at $-20^{\circ} \mathrm{C}$ without thawing. To take into account the effect of long storing period on the results sera from 30 healthy blood donors which had been stored for the same time and under the same conditions were studied. The other series included 147 serum samples from

Table 1 Patients and controls

\begin{tabular}{lrllll}
\hline $\begin{array}{l}\text { Grade of } \\
\text { arthritis }\end{array}$ & Men & Women & $\begin{array}{l}\text { Age* } \\
\text { (vears) }\end{array}$ & \multicolumn{2}{l}{ HLA-B27 } \\
\hline++ & 12 & 7 & $35(2-62)$ & 15 & 4 \\
+ & 5 & 4 & $36(22-50)$ & 1 & 8 \\
- & 10 & 13 & $30(14-72)$ & 6 & 17 \\
Normal controls & 25 & 25 & $39(19-64)$ & \\
\hline
\end{tabular}

${ }^{*}$ Values are mean (range).
36 patients with yersiniosis, 22 of them with arthritis and 14 with gastroenteritis. The sera were stored at $\frac{\nabla}{\omega}$. $-20^{\circ} \mathrm{C}$ for no longer than two years and not thawed more than three times before the final experiments. The effect of thawing has been discussed in a previous paper describing the methodology in closer $\frac{C}{\sigma}$ detail. ${ }^{2}$ Sera from 50 healthy blood donors were $\frac{\mathrm{m}^{2}}{\mathrm{~T}}$ used as controls (Table 1).

DETECTION OF YERSINIA SPECIFIC IMMUNE ڤึ COMPLEXES

We have recently developed an ELISA for the detection of Ig class specific, yersinia ICs, which is $\vec{\omega}$ described in detail elsewhere. ${ }^{12} 13$ In this assay yersinia specific ICs were captured via the antibody? to polystyrene microtitre plates by rabbit antihuman immunoglobulins, and the existence of $Y$ entero- $+v$ colitica $\mathrm{O}: 3$ antigens was demonstrated using Fab $\vec{N}$ fragments of alkaline phosphatase conjugated anti- $\overrightarrow{0}$ body against the same serotype (anti-yersinia (Fab)-글 AP conjugate). To standardise the test each plate $\vec{T}$ included three controls: a positive serum with high $\frac{\mathbb{O}}{\sigma}$ amount of yersinia-immunoglobulin complexes of all three immunoglobulin classes, buffer $(5 \% \stackrel{\text { g }}{2}$ normal rabbit serum-PBS), and a pool consisting of sera from 50 healthy blood donors.

The results were expressed as enzyme immuna.assay units (EIUs) as follows:

$$
\text { ElU sample }=\frac{O D_{\text {sample }}-O D_{\text {huffer }}}{O D_{\text {penitive standard }}-O D_{\text {huffer }}} \times 1(0)
$$

where OD is the optical density.

EIUs of 50 normal sera were measured separately⿳亠丷厂 and mean values and standard deviations were calculated. EIUs over 2 SD added to the EIUs of pooled normal control sera included on each plate were taken as positive. Grade of positivity was. determined as follows: + with EIUs 2 SD to 4 SD' above the mean of normal controls, ++ with values $4 \mathrm{SD}$ to $6 \mathrm{SD}$, and +++ with EIUs over 6 SDsô above the mean of normal controls.

SPECIFICITY OF BINDING OF ANTI-YERSINIA ( Fab)-AP CONJUGATE TO THE SAMPLES The specificity of anti-yersinia (Fab) has earlier been shown by inhibiting its binding to $Y$ enterocoli-or tica $\mathrm{O}: 3$ coated wells by several Gram negative bacteria. ${ }^{13}$ In the present work the specificity was further controlled by inhibiting its binding to the ICs detected. For this purpose a serum highly positive for yersinia specific ICs of IgM, IgG, and IgA classes was used. The serum was used in the ELISA as described above, except that $Y$ enterocolitica $\mathrm{O}: 3^{3}$ bacteria were added in different concentrations simultaneously with the anti-yersinia (Fab)-AP con jugate. 
DETERMINATION OF RHEUMATOID FACTORS Rheumatoid factors were determined in all sera positive for yersinia specific ICs by both the WaalerRose test and an ELISA for IgM rheumatoid factors. $^{14}$

DETECTION OF ANTIGEN NON-SPECIFIC IMMUNE COMPLEXES

Two methods of detecting antigen non-specific ICs, consisting mainly of $\mathrm{IgG}$, were used. Platelet ${ }^{125} \mathrm{I}$ labelled staphylococcal protein A test (PIPA) was performed as described by Kekomäki and Penttinen $^{15}$ and conglutinin binding ELISA (KgBELISA) according to Wager and Lindström. ${ }^{16}$

DETECTION OF ANTI-YERSINIA ANTIBODIES Antibodies to $Y$ enterocolitica $\mathrm{O}: 3$ were measured by an ELISA. ${ }^{10}$ "11

TISS UE TYPING

The peripheral blood lymphocytes were typed for HLA-B27 antigen by a two stage microlymphocytotoxicity test (Histognost-B27, Behring Institut, Behringwerke AG, Marburg, W Germany).

STATISTICAL ANALYSIS

The statistical significance of the differences in the amount of yersinia specific ICs between patients with and without reactive arthritis was evaluated with Mann-Whitney's U test.

\section{Results}

YERSINIA SPECIFIC IMMUNE COMPLEXES

Since differences were not found in the occurrence of yersinia specific ICs between the patients with grade + and grade ++ arthritis, they are here presented as one group.

\section{Yersinia specific IgM complexes}

During the first two months after onset of the infection yersinia-IgM complexes occurred in the sera of 10 of 23 arthritic patients, and five sera were highly $(+t,+++)$ positive (Fig. 1). Four of 23 non-arthritic patients were positive for yersinia specific IgM complexes; one was highly positive $(++)$. The difference between arthritic and nonarthritic patients was significant $(p<0.02)$. When followed up further, high values seen in patients with arthritis decreased and the difference between the two groups diminished (Fig. 1). At four to six months, however, six of 20 patients with arthritis and only one of seven patients without arthritis had IgM complexes. At eight to 12 months four arthritic and two non-arthritic patients had IgM complexes. (One arthritic patient had IgM complexes both at eight to 10 and at 10 to 12 months, see Fig. 1.) In addition, the complexes were still found in one arthritic patient at 15 months after onset of the

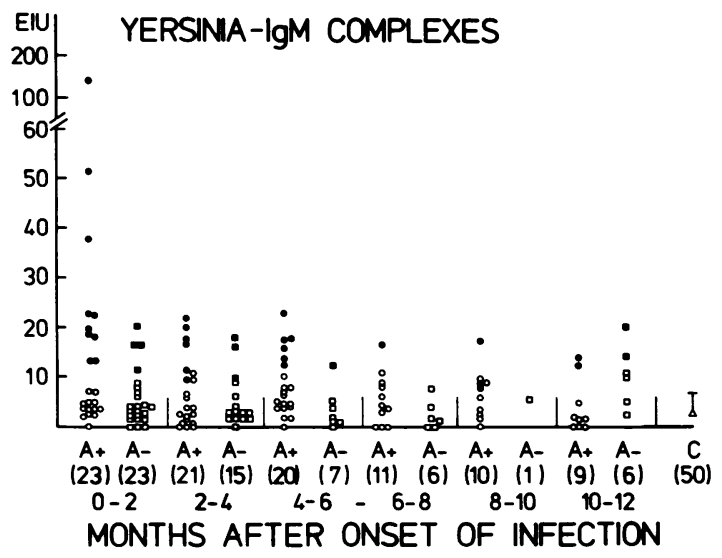

Fig. 1 One year follow up of occurrence of yersinia-IgM complexes in the sera of 51 patients with recent yersiniosis. The patients were divided into two groups depending on whether they developed reactive arthritis $(A+)$ or not $(A-)$. The results are expressed as EIA units; the limit between positive and negative values was calculated separately for each assay (see text). Positive values, i.e., more than $2 S D$ above the mean of normal controls are indicated by black symbols $(\mathrm{O}, \mathrm{a})$, and negative values by open symbols $(\mathrm{O}$, $\square)$. Each symbol represents one patient. Mean value $(+S D)$ of yersinia specific ICs measured in the sera of 50 healthy blood donors is also indicated $(\triangle)$.

infection. Altogether, yersinia-IgM complexes were found in 12 of the $28(43 \%)$ patients with arthritis and in four of the $23(17 \%)$ patients without arthritis.

Yersinia specific $\operatorname{Ig} G$ and $\operatorname{IgA}$ complexes Yersinia-IgG complexes were detected in three of 28 $(11 \%)$ arthritic patients and three of $23(13 \%)$ non-arthritic patients. During the first two month follow up four of $28(14 \%)$ patients with arthritis had yersinia-IgA complexes, three of them in high amounts $(++,+++)$. One of the patients still had a positive level of $\operatorname{IgA}$ complexes at 10-12 months. Non-arthritic patients had no IgA complexes.

\section{$H L A-B 27$}

Occurrence of yersinia specific ICs of any Ig class did not correlate with the occurrence of HLA-B27 (Table 2).

\section{Individual follow up}

For an individual presentation two patients were chosen from both the arthritic and non-arthritic group on the basis of having the highest level of yersinia specific ICs within two months of the onset of infection (Fig. 2). All four still had detectable levels of yersinia-immunoglobulin complexes at 
Table 2 Distribution of yersinia specific ICs in patients according to $H L A-B 27$

\begin{tabular}{|c|c|c|c|c|}
\hline \multirow{3}{*}{$\begin{array}{l}\text { Grade of } \\
\text { arthritis }\end{array}$} & \multicolumn{4}{|c|}{ Yersinia specific ICs } \\
\hline & \multicolumn{2}{|l|}{ Positive } & \multicolumn{2}{|l|}{ Negative } \\
\hline & $H L A-B 27+$ & $H L A-B 27-$ & $H L A-B 27+$ & $H L A-B 27-$ \\
\hline++ & $8^{*}$ & 1 & 7 & 3 \\
\hline+ & 1 & 4 & 0 & 4 \\
\hline- & 1 & 5 & 5 & 12 \\
\hline
\end{tabular}

*Values show number of patients with yersinia specific ICs.

10-12 months after the onset of infection. Interestingly, both of the patients with arthritis had prolonged joint symptoms during the year. The patients without arthritis had not suffered from any symptoms after recovering from the gastroenteritis.

SPECIFICITY OF BINDING OF ANTI-YERSINIA (Fab)-A P CONJUGATE TO THE SAMPLES

Addition of $Y$ enterocolitica $\mathrm{O}: 3$ bacteria in concentrations of $60 \mu \mathrm{g} / \mathrm{ml}$ or more simultaneously with anti-yersinia (Fab) conjugate resulted in clear inhibition of the highly positive values given by an uninhibited sample. The inhibition was observed in the assays of yersinia-specific ICs of all three Ig classes. These findings, together with previous experiments, ${ }^{12}$ confirm the specificity of the binding of the anti-yersinia (Fab)-AP conjugate.

DETERMINATION OF RHEUMATOID FACTORS All the sera positive for yersinia specific ICs were negative for rheumatoid factors.

YERSINIA SPECIFIC ICS COMPARED WITH ICS尽 DETECTED BY ANTIGEN NON-SPECIFIC ڤั METHODS

Fourteen samples, each from different patients, had $\stackrel{\circ}{\circ}$ earlier been analysed for the occurrence of circulat $-\overrightarrow{\vec{\omega}}$ ing ICs by two antigen non-specific methods, KgB-ELISA and PIPA. Yersinia-IgM complexes were detected in three of these 14 sera. $\mathrm{KgB}$-ELISA gave a positive result in all three and PIPA in one. के Yersinia-IgG complexes were observed in one nonarthritic patient, who had also ICs detected by non- specific methods, while yersinia-IgA complexes음 were found in none of the samples. Among the seranegative for yersinia specific complexes of any isotype, ICs were detected by one or both of theo non-specific methods in nine cases. In sera of two patients ICs were not detected by any of the methods.

The reason for the difference in the occurrence $8 \mathrm{f}=$ ICs detected by antigen specific and antigen nom specific methods might be that $(a)$ sera with positive result in antigen non-specific assays, but
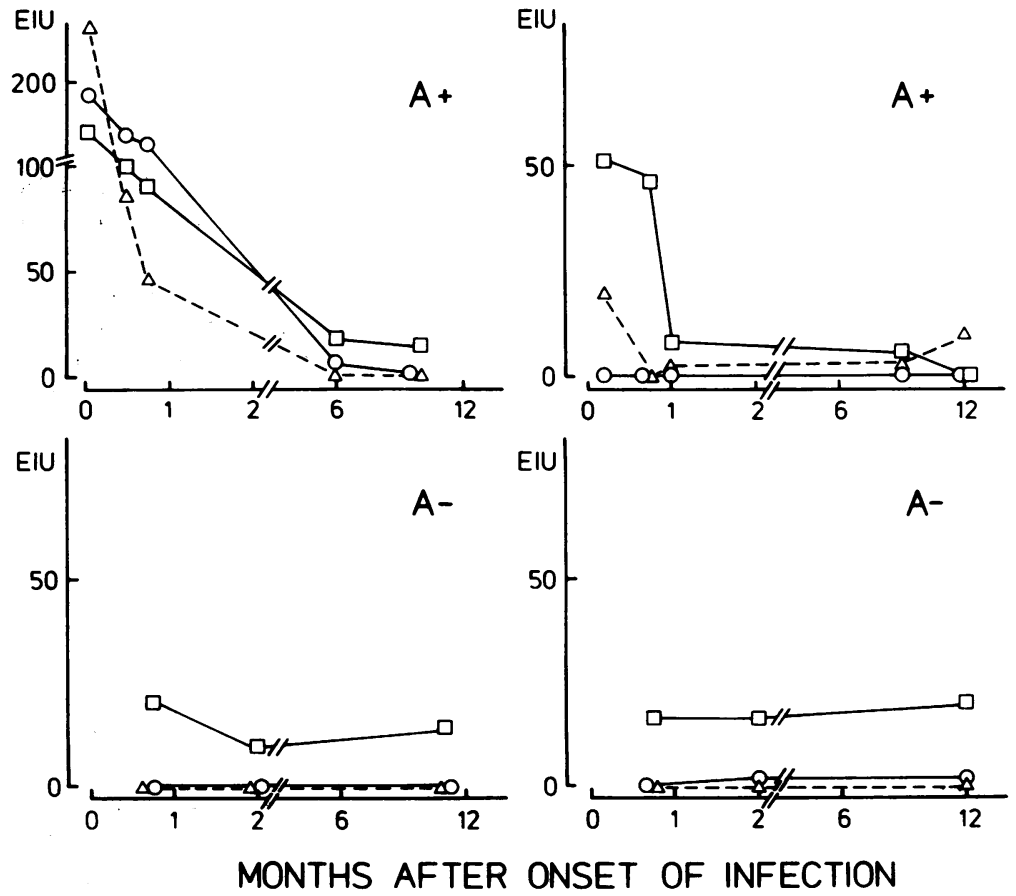

Fig. 2 Follow up of yersinia specific ICs in the sera of four patients. Two patients with the highest level of yersinia specific ICs 응 at the early stage of the disease were chosen from both the arthritic $(A+)$ and non-arthritic $(A-)$ group. Yersinia-IgM complexes ( $\square$ ), IgG N complexes (O), and IgA complexes $(\triangle)$ are presented separately. 
negative for yersinia specific complexes, do not contain yersinia antigen within the complexes, or that $(b)$ our antiserum against yersinia does not recognise all yersinia antigens in ICs; our antiserum was raised by using bacteria grown at room temperature, which does not favour expression of the plasmid associated proteins.

COMPARISON OF THE OCCURRENCE OF YERSINIA SPECIFIC ICS AND IgA CLASS ANTI-YERSINIA ANTIBODIES

Since IgA-anti-yersinia antibodies are known to persist even for years in patients developing arthritis, ${ }^{1011} 17$ they were studied in the samples taken more than eight months after the onset of infection. IgA class antibodies were found in seven out of eight patients with prolonged occurrence of yersinia-IgM complexes, the eighth patient without persisting IgA had IgA complexes. IgA-anti-yersinia antibodies were also observed in 11 arthritic patients and in one non-arthritic individual, who had no yersinia specific complexes. Tissue typing of the eight patients with prolonged occurrence of yersinia specific ICs showed that three of the six arthritic patients were HLA-B27 positive and the two nonarthritic patients were HLA-B27 negative.

\section{CLINICAL FEATURES IN PATIENTS WITH PERSISTING ICS}

The six patients with arthritis and with persisting ICs showed some interesting features. At the early stage of the infection their erythrocyte sedimentation rates were $101,87,75,57,50$, and $2 \mathrm{~mm} / \mathrm{h}$, whereas values of 24 and $12 \mathrm{~mm} / \mathrm{h}$ were recorded for the two patients without arthritis. Five of the six arthritic patients had prolonged joint symptoms over eight months after the onset of the infection. One of them had to be pensioned off owing to development of severe chronic arthritis. In another ankylosing spondylitis is suspected. One patient had developed chronic persisting hepatitis; no possible aetiologic background other than yersinia infection has been found. A patient with grade ++ arthritis lasting up to one year has thereafter had mild intermittent arthralgia. One of the patients has suffered from polyarthralgia for over two years.

Only two of the eight patients with persisting ICs had not received antibiotics; they both were in the arthritic group.

\section{Discussion}

Our findings show that patients developing arthritis after yersinia infection have significantly more $(p<0.02)$ yersinia specific IgM complexes than patients without this postinfection complication. The difference applies to the first two months after onset of the infection and disappears thereafter. Also Kekomäki et al found that antigen nonspecific ICs as measured by PIPA decreased significantly with time in patients with arthritis. ${ }^{\times}$In the present series yersinia specific $\operatorname{IgA}$ complexes were detected in four out of 28 patients with arthritis, but in none of the 23 patients without arthritis.

There are very few examples in the literature of ICs containing a known antigen during a follow up. HBsAg-IgM complexes, however, have been shown to persist in the patients with a chronic liver disease after acute viral, type B hepatitis. Such complexes were described as an early marker of chronic evolution; HBsAg-IgA or -IgG complexes were not found in these patients. ${ }^{18}{ }^{19}$ Inman et al demonstrated a 60000 dalton component specific for Lactobacillus casei in ICs of a patient with infective endocarditis up to one month after onset of the infection. $^{20}$

There may be several explanations for the difference in the occurrence of yersinia specific ICs in patients with and without arthritis. Better absorption of the antigen through the gut of patients with arthritis would lead to increased levels of yersinia specific circulating complexes. Patients with arthritis often have only a mild diarrhoea, if any at all, ${ }^{21}$ which would mean ineffective bacterial elimination and increased penetration of the antigen from the gut. The patients with arthritis might also have increased permeability of the gut leading to higher levels of yersinia specific ICs, like patients with ankylosing spondylitis, who were recently reported to have a significant increase in intestinal permeability when compared with the controls. ${ }^{22}$

The properties of the bacterial strain itself could also be responsible for higher levels of yersinia specific complexes observed in patients with arthritis. One possibility is molecular mimicry, similarity of the antigen to the patient's own structures, which could lead to an ineffective elimination of the antigen not recognised as foreign. Cross reactivity between HLA-B27 and certain antigens of arthritis causing bacteria has recently been shown by the use of monoclonal antibodies. ${ }^{23}{ }^{24} \mathrm{~A}$ hypothesis of cross tolerance had earlier been suggested on the basis of cross reactions found between klebsiella and HLAB27 positive cells from patients with ankylosing spondylitis. ${ }^{25}$ In our study, however, a high level and prolonged occurrence of yersinia specific complexes were demonstrated both in HLA-B27 positive and negative patients (Table 2).

Prolonged IC formation was observed both in arthritic and in non-arthritic patients and in both HLA-B27 positive and negative individuals. Even more than eight months after onset of the infection 
yersinia specific complexes were demonstrated in six patients with arthritis and in two without arthritis. The two non-arthritic patients were those who showed the highest level of yersinia-IgM complexes among the non-arthritic patients at an early stage of the disease. Five of the six patients with arthritis had also persisting IgAclass anti-yersinia antibodies, and the one without detectable IgA class antibodies had IgA complexes. Interestingly, five of the arthritic patients still had prolonged joint symptoms one year after onset of the infection. Also the two nonarthritic patients with prolonged occurrence of yersinia specific complexes had persisting IgA-antiyersinia antibodies, which are not usually seen in patients without arthritis. ${ }^{11} 17$ These eight patients with prolonged occurrence of yersinia specific ICs together with persisting $\operatorname{IgA}$ are demonstrative examples of the possibility that yersiniae or some parts of it hide within the patient's body for prolonged periods.

There were also several cases where our test for yersinia specific ICs was negative, possibly owing to the attachment of free antibodies to antihuman immunoglobulins bound to the solid phase, thereby preventing detection of ICs. The ability of the method to detect ICs of all three Ig classes has earlier been demonstrated, however, with preformed ICs. ${ }^{13}$ Also, sera with yersinia specific ICs had a high level of anti-yersinia antibodies. There were only two exceptions: in two patients a high level of yersinia-IgM complexes was observed at an early stage of the disease in the absence of antiyersinia antibodies, which later on became detectable. Therefore, demonstration of yersinia specific ICs may also have diagnostic significance at an early stage of the yersinia infection.

Prolonged occurrence of yersinia specific ICs in eight patients together with the persisting IgA-antiyersinia antibodies possibly indicates persistence of the antigen within the patient. The role of yersinia specific IgM complexes at an early stage of the disease and their significance in the pathogenesis of the arthritis will be studied further.

Supported by the Finnish Medical Foundation. the Research and Science Foundation of Farmos Company. the Emil Aaltonen Foundation. and the US Public Health Service (No 5 RO1 AM 33311, awarded by National Institute of Arthritis. Diabetes. and Digestive and Kidney Discases).

\section{References}

1 Williams R C. Jr. Immune complexes in human diseases. Annu Rev Med 1981: 32: 13-28.

2 Manicourt D H. Orloff S. Immune complexes in polyarthritis after Salmonella gastrocnteritis, $J$ Rheumatol 1981; 8: 613-20.

3 Jennette J C. Ferguson A L. Moore M A. Freeman D G. IgA nephropathy associated with seronegative spondyloarthropathics. Arthritis Rheum 1982: 25: 144-9.

4 Forsström J. Viander M. Lehtonen A. Ekfors T. Yersinia enterocolitica infection complicated by glomerulonephritis. Scand J Infect Dis 1977: 9: 253-6.

5 Friedberg M. Larsen S. Denneberg T. Yersinia enterocolitica and glomerulonephritis. Lancet 1978: i: 498-9.

6 Hall R P. Gerber L H. Lawley T J. IgA-containing immune complexes in patients with psoriatic arthritis. Clin Exp Rheumatol 1984: 2: 221-5.

7 Johnson K J. Wilson B S. Till G O. Ward P A. Acute lung injury in rat caused by immunoglobulin $A$ immune complexes. $J$ Clin Invest 1984: 74: 358-69.

8 Kekomäki R. Granfors K. Leino R. Penttinen K. Lindström P-L. Wager $O$. Clinical correlates of circulating immune complexes in patients with recent yersiniosis. J Infect Dis 1983: 148: 223-9.

9 Leirisalo M. Gripenberg M. Julkunen I. Repo H. Circulating immune complexes in yersinia infection. $J$ Rheumatol 1984: 11: $365-8$.

10 Granfors K. Measurement of immunoglobulin M (IgM). IgG. and IgA antibodies against Yersinia enterocolitica by enzymelinked immunosorbent assay: persistence of serum antibodies during disease. J Clin Microbiol 1979: 9: 336-41

11 Granfors K. Quantitation of $\operatorname{lgM}$. IgG. and $\lg A$ class antibodies against yersinia in human serum. Thesis. Annales Universitas Turkuensis 1979: AII: 61 .

12 Lahesmaa-Rantala R. Granfors K. Toivanen A. Quantitation of versinia-immunoglobulin complexes by ELISA. [Abstract]. Scaind J Immunol 1984: 20: 167.

13 Lahesmaa-Rantala R. Granfors K. Toivanen A. Detection of circulating yersinia-immunoglobulin complexes by enzymeimmunoassay (EIA). J Immunol Methods 1986: 89: 191-9.

14 Viljanen MK. Ruuskanen O. Granberg C. Salmi TT. Serological diagnosis of pertussis: IgM. IgA and IgG antibodies again 8 Bordetella pertussis measured by enzyme-linked immunosore bent assay (ELISA). Scand J Infect Dis 1982: 14: 117-22.

15 Kekomäki R. Penttinen K. Platelets and ${ }^{125}$ I-labelled staphyle coccal protein $\mathrm{A}$ in the detection of immune complexes in serum. J Clin Lab Immunol 1979: 1: 305-9.

16 Wager $\mathrm{O}$. Lindström $\mathrm{P}$. Interference by rheumatoid factor and Clq with detection of IgG complexes: studies of model systems by ELISA. Scand J Immunol 1982: 15: 319-28.

17 Granfors K. Viljanen M K. Tiilikainen A. Toivanen A. Persistence of $\operatorname{IgM}$. IgG. and $\operatorname{IgA}$ antibodies to yersinia and versinia arthritis. J Infect Dis 1980: 141: 424-9.

18 Careoda F. de Franchis R. Monforte A. et al. Persistence of circulating $\mathrm{HBsAg} / \mathrm{lgM}$ complexes in acute viral hepatitis, type B: an early marker of chronic evolution. Lancet 1982: ii: $358-60$.

19 Palla M. Rizzi R. Toti M. et al. Complexes of hepatitis B surface antigen and immunoglobulin $M$ in the sera of patients with hepatitis B virus infection. Infect Immun 1983; 41: 950-8.

20 Inman R D. Rosenberg R A. Redecha P B, Christian C L. Characterization of sequential immune complexes in infective endocarditis by Western blot analysis. J Immunol 1984; 133: 응 217-21.

21 Leino R. Human yersiniosis. A clinical study with special $D$ reference to lymphocyte transformation in yersinia arthritis. 을 Turku: Turku University. 1982. (Thesis.)

22 Smith M D. Gibson R A. Brooks P M. Abnormal bowel o permeability in ankylosing spondylitis and rheumatoid arthritis. N $J$ Rheumatol 1985: 12: 299-305.

23 Van Bohemen Ch G. Grumet F C. Zanen H C. Identification of $\tilde{\omega}$ HLA-B27M1 and -M2 cross-reactive antigens in klebsiella, $O$ shigella and yersinia. Immunology 1984: 52: 607-10.

24 Kono D H. Ogasawara M. Effros R B. Park M S. Waldord R L. Yu D T Y. Ye-1, a monoclonal antibody that cross-reacts with $\mathbb{D}$ HLA-B27 lymphoblastoid cell lines and an arthritis causing? bacteria. Clin Exp Immunol 1985: 61: 503-8.

25 Ebringer A. The cross-tolerance hypothesis, HLA-B27 and ankylosing spondylitis. $B r J$ Rheumatol 1983: 22 (suppl 2): 53-66. 